\title{
Pulmonary ARTERY INTRAMURAL HEMATOMA: UNUSUAL COMPLICATION OF AORTIC DISSECTION
}

\section{Felipe Homem Valle ${ }^{1}$, Marcelo Gib², Felipe Soares Torres ${ }^{3}$}

A 56 year-old patient presented to the emergency room with chest pain and $26 \mathrm{mmHg}$ blood pressure gap between right arm and left lower limb. The hypothesis of aortic dissection was evaluated through chest CT, which showed a Stanford type A aortic dissection with extension through the pulmonary artery and the presence of an intramural hematoma extending along the main and right pulmonary arteries (Figure 1). The intramural hemorrhage extended along the right lower lobe pulmonary arteries, and there was resultant peribronchovascular ground glass opacity, consistent with pulmonary hemorrhage (Figure 2). The patient underwent surgical repair of the type A dissection. Ten days after surgery, she was discharged asymptomatic. Chest CT was repeated after three months and complete regression of all abnormalities was observed (Figure 3).

The extension of Stanford type A aortic dissection through pulmonary artery is a result of rupture through the posterior aspect of the aortic root into the common adventitia of the aorta and pulmonary artery ${ }^{1}$. As the blood continues to dissect into the more peripheral pulmonary branches, it can lead to pulmonary hemorrhage. Sueyoshi et al. demonstrated that the extension of pulmonary hemorrhage into alveoli and double barrel aortic dissection are predictors of poor prognosis in this scenario².

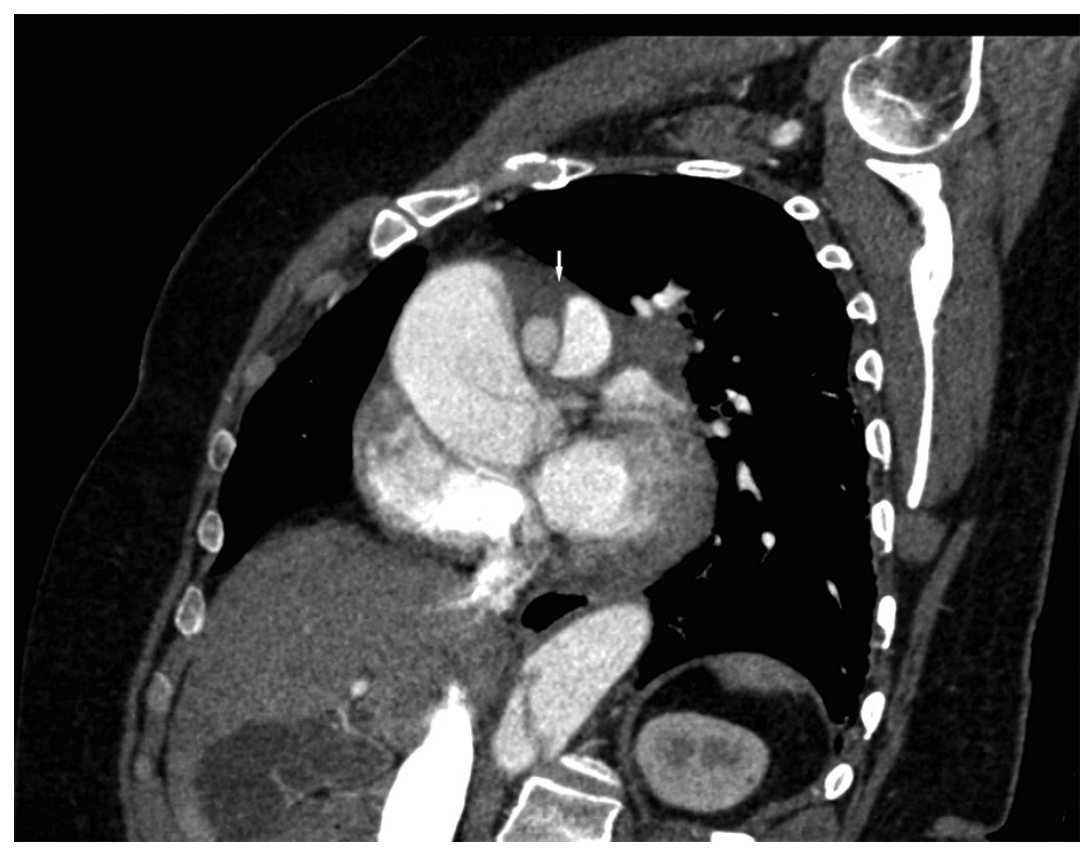

Figure 1: Computed tomography angiography of the chest showing a Stanford type A aortic dissection with contrast extravasation into the wall of the main pulmonary artery (arrow).
Clin Biomed Res. 2015;35(3):167-168 1 Divisão de Cardiologia, Hospital de Clínicas de Porto Alegre. Porto Alegre, RS, Brazil.

2 Divisão de Cirurgia Cardiovascular, Hospital de Clínicas de Porto Alegre. Porto Alegre, RS, Brazil.

3 Divisão de Radiologia, Hospital de Clínicas de Porto Alegre. Porto Alegre, RS, Brazil.

Corresponding author:

Felipe Homem Valle

E-mail: felipehvalle@gmail.com

Division of Cardiology, Hospital de Clínicas de Porto Alegre.

Rua Ramiro Barcelos, 2350

90035-903, Porto Alegre, RS, Brazil. 


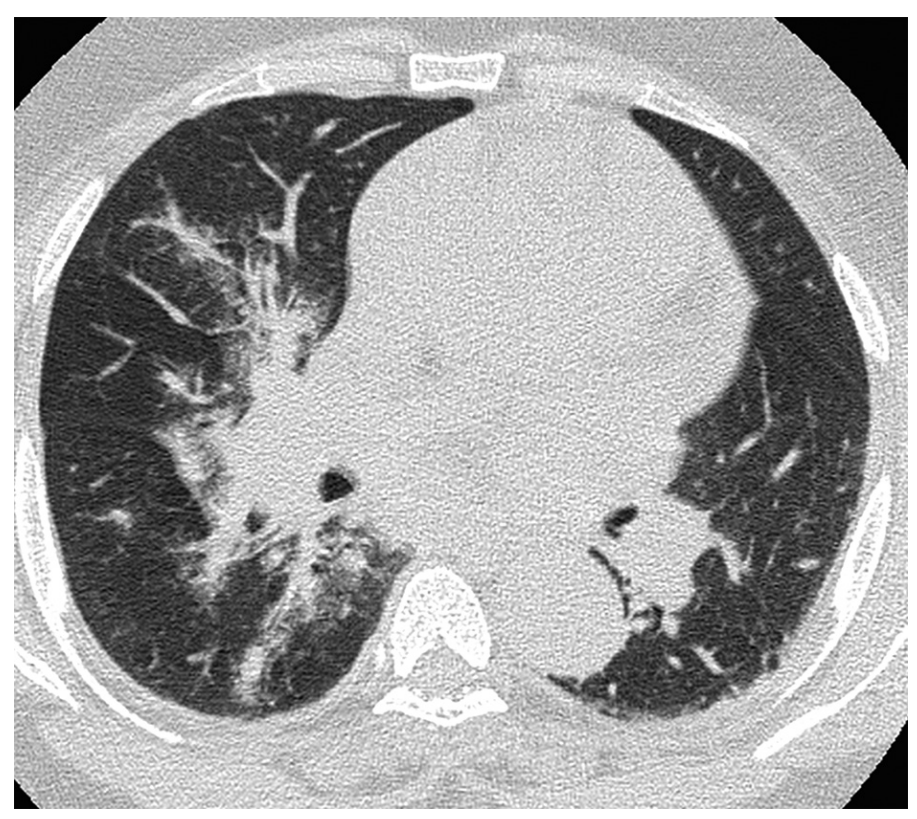

Figure 2: Axial computed tomography of the chest showing peribronchovascular ground glass opacity indicating extension of the hemorrhage into the interstitium and alveoli.

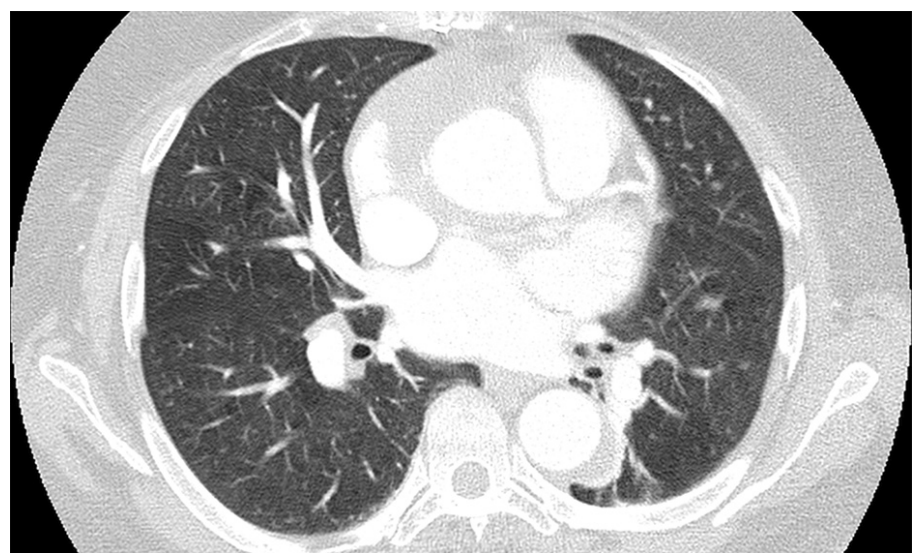

Figure 3: Axial computed tomography of the chest showing regression of peribronchovascular ground glass opacity, previously observed in Figure 2.

\section{REFERENCES}

1. Panicek DM, Ewing DK, Markarian B, Heitzman ER. Interstitial pulmonary hemorrhage from mediastinal hematoma secondary to aortic rupture. Radiology. 1987;162(1):165-6. http://dx.doi. org/10.1148/radiology.162.1.3786757. PMid:3786757.

2. Sueyoshi E, Matsuoka Y, Sakamoto I, Uetani M. CT and clinical features of hemorrhage extending along the pulmonary artery due to ruptured aortic dissection. Eur Radiol. 2009;19(5):1166-74. http://dx.doi. org/10.1007/s00330-008-1272-7. PMid:19156424. 